\title{
Clinical outcomes in patients admitted to hospital with cervical spine fractures or with hip fractures
}

\author{
Joshua Baxter ${ }^{1} \cdot$ Radcliffe Lisk $^{2} \cdot$ Ahmad Osmani $^{2} \cdot$ Keefai Yeong $^{2} \cdot$ Jonathan Robin $^{3} \cdot$ David Fluck $^{4}$. \\ Christopher Henry Fry ${ }^{5}$. Thang Sieu Han $^{6}$ (D)
}

Received: 28 August 2020 / Accepted: 9 November 2020 / Published online: 26 November 2020

(c) The Author(s) 2020

\begin{abstract}
Patients admitted with a cervical fracture are twice as likely to die within 30 days of injury than those with a hip fracture. However, guidelines for the management of cervical fractures are less available than for hip fractures. We hypothesise that outcomes may differ between these types of fractures. We analysed 1359 patients (406 men, 953 women) with mean age of 83.8 years (standard deviation $=8.7$ ) admitted to a National Health Service hospital in 2013-2019 with a cervical $(7.5 \%)$ or hip fracture $(92.5 \%)$ of similar age. The association of cervical fracture (hip fracture as reference), hospital length of stay (LOS), co-morbidities, age and sex with outcomes (acute delirium, new pressure ulcer, and discharge to residential/ nursing care) was assessed by stepwise multivariate logistic regression. Acute delirium without history of dementia was increased with cervical fractures: odds ratio $(\mathrm{OR})=2.4,95 \%$ confidence interval $(\mathrm{CI})=1.3-4.7$, age $\geq 80$ years: $\mathrm{OR}=3.5$ $(95 \% \mathrm{CI}=1.9-6.4)$, history of stroke: $\mathrm{OR}=1.8(95 \% \mathrm{CI}=1.0-3.1)$ and ischaemic heart disease: $\mathrm{OR}=1.9(95 \% \mathrm{CI}=1.1-3.6)$; pressure ulcers was increased with cervical fractures: $\mathrm{OR}=10.9(95 \% \mathrm{CI}=5.3-22.7)$, LOS of $2-3$ weeks: $\mathrm{OR}=3.0(95 \%$ $\mathrm{CI}=1.2-7.5)$ and $\mathrm{LOS}$ of $\geq 3$ weeks: $\mathrm{OR}=4.9,95 \% \mathrm{CI}=2.2-11.0$; and discharge to residential/nursing care was increased with cervical fractures: $\mathrm{OR}=3.2(95 \% \mathrm{CI}=1.4-7.0)$, $\mathrm{LOS}$ of $\geq 3$ weeks: $\mathrm{OR}=4.4$ (95\% $\mathrm{CI}=2.5-7.6)$, dementia: $\mathrm{OR}=2.7$ (95\% $\mathrm{CI}=1.6-4.7)$, Parkinson's disease: $\mathrm{OR}=3.4$ (95\% $\mathrm{CI}=1.3-8.8)$, and age $\geq 80$ years: $\mathrm{OR}=2.7$ (95\% $\mathrm{CI}=1.3-5.6)$. In conclusion, compared with hip fracture, cervical fracture is more likely to associate with acute delirium and pressure ulcers, and for discharge to residency of high level of care, independent of established risk factors.
\end{abstract}

Keywords Geriatrics $\cdot$ Pressure ulcers $\cdot$ Length of stay $\cdot$ Mortality $\cdot$ Discharge destination

Thang Sieu Han

thang.han@rhul.ac.uk

1 Birmingham Medical School, College of Medical and Dental Sciences, University of Birmingham, Birmingham B15 2TT, UK

2 Department of Orthogeriatrics, Ashford and St Peter's NHS Foundation Trust, Guildford Road, Chertsey KT16 0PZ, Surrey, UK

3 Department of Medicine, Ashford and St Peter's NHS Foundation Trust, Guildford Road, Chertsey KT16 0PZ, Surrey, UK

4 Department of Cardiology, Ashford and St Peter's NHS Foundation Trust, Guildford Road, Chertsey KT16 0PZ, Surrey, UK

5 School of Physiology, Pharmacology and Neuroscience, University of Bristol, Bristol BS8 1TD, UK

6 Institute of Cardiovascular Research, Royal Holloway, University of London, Egham TW20 0EX, Surrey, UK

\author{
Abbreviations \\ CI Confidence interval \\ LOS Length of stay \\ OR Odds ratio \\ SD Standard deviation
}

\section{Introduction}

Hip fracture is a disabling condition affecting many older individuals worldwide, with incidence rates being greatest among high income countries, particularly those further from the equator [1]. The estimated lifetime risk of a hip fracture is 23\% in European women and 11\% in European men [2]. In 1990, the global number of hip fractures was 1.26 million. Because of the steep rise in the rates of hip fractures with age and the growing ageing population, their number is expected to rise to 4.5 million by 2050 [3]. Hip fracture is a prognostic indicator of mortality and disability. 
A substantial proportion of survivors require long-term high levels of care, imposing an enormous burden on health-care systems [1, 3-5]. The mean cost for an index hospitalisation has been estimated to be over US $\$ 10,000$, and health and social care costs almost $\$ 44,000$ at 1 year [6].

By contrast, cervical spine fractures occur far less frequently than hip fractures [7], but the incidence also increases with age [8] and has been rising in recent years. A study of 167,278 older US adults admitted with cervical fractures showed a big increase in the rates of hospitalisation (from 26/100,000 to 68/100,000) and mortality (from $3 / 100,000$ to 6/100,000) between 2001 and 2010 [9]. Mortality among hospital patients with cervical fractures has been reported to be $8-14 \%[9,10]$, and $28-37 \%$ within 1 year of the fracture [11-14]. Unlike hip fractures, the majority of cervical fractures are treated non-surgically. However, supportive treatment such as cervical spine immobilisation appears to associate with a number of complications including pressure sores, raised intracranial pressure, swallowing and breathing difficulties, and exacerbation of delirium [15].

A study of over a million patients showed that patients who sustained a cervical fracture were twice as likely to die within 30 days of the injury than those who sustained a hip fracture [14]. However, guidelines for the management of cervical fractures is less comprehensive compared to those for hip fractures $[7,16]$. Because the management approaches to these two age-related acute conditions remain highly contrasting [14], we hypothesise that post-fracture outcomes in patients with cervical fractures may differ from those in patients with hip fractures.

\section{Methods}

\section{Study design, participants and setting}

We conducted a cross-sectional study of older individuals (aged 60-103 years) admitted with cervical and hip fractures to a National Health Service hospital between 2013 and 2019, serving a catchment population of over 410,000 people.

\section{Data collection}

Data were prospectively collected by a Trauma Coordinator for patients admitted with a hip or cervical fracture from the time of admission to discharge [17-19]. Co-morbidities were identified from electronic record databases by disease codes defined by the International Classification of Diseases 10 [20]. Data consisted of clinical characteristics and care quality was updated regularly into a database managed by the lead orthogeriatrician to ensure completeness and accuracy of data entry. Demographic and clinical information included age, sex, residency prior to admission, dates of admission and discharge from which length of stay (LOS) in hospital was calculated, mental status (acute delirium) at admission, new pressure ulcers developed during admission and discharge destination.

\section{Categorisation of variables}

Pressure ulcers were defined as grade 2 or above and newly acquired in hospital. LOS in hospital was categorised into three groups: $<2$ weeks, $2-3$ weeks and $\geq 3$ weeks, and age into two groups: $<80$ and $\geq 80$ years. Change to discharge destination was defined as those who came from their own home before hospital admission, but were transferred to places of higher level of care including rehabilitation units, residential or nursing care. Acute delirium was based on standard clinical assessment tool and only patients without a history of dementia were included for this particular analysis.

\section{Statistical analysis}

Continuous group data are summarised as mean values \pm standard deviation (SD). Differences between categorical outcome variables were assessed by Chi-squared tests. Stepwise multivariate logistic regression was used to assess the association of: the types of fractures; LOS; chronic comorbidities including dementia, stroke, Parkinson's disease, ischaemic heart disease and diabetes; age and sex (dependent variables) with outcomes including: acute delirium; new pressure ulcers; and discharge to residence of high level of care (residential or nursing care). All independent variables were entered simultaneously; only variables associate significantly with outcome measures are automatically selected by this stepwise regression technique and presented in our results. Analyses were performed using IBM SPSS Statistics, v25.0 (IBM Corp., Armonk, NY).

\section{Results}

The data of a total of 1359 patients (406 men, 953 women) aged 83.8 years $(\mathrm{SD} \pm 8.7)$ were analysed. Most patients came from their own home (81.3\%), followed by residential/ nursing care (12.0\%) and rehabilitation (6.7\%). 102 (7.5\%) patients were admitted with cervical fractures with mean age of 82.7 years $(\mathrm{SD} \pm 9.8)$ and 1257 (350 men, 907 women) patients admitted with hip fractures with mean age of 83.9 years $(S D \pm 8.6)$. There was no age difference between the two groups of fractures $(p=0.214)$. Falls were the main cause of fractures, occurring in $95.5 \%$ of hip fractures and $93.1 \%$ of cervical fractures. The remaining causes of cervical fractures $(6.9 \%)$ were patients involved in road traffic or 
other high-impact accidents. There were $28.6 \%$ of patients with co-exiting dementia, $15.2 \%$ with stroke, $4.2 \%$ with Parkinson's disease, $9.9 \%$ with ischaemic heart disease and $13.5 \%$ with diabetes. The proportions of patients with hospital LOS $<2$ weeks, $2-3$ weeks and $\geq 3$ weeks were 68.7 , 15.7 and $15.6 \%$, respectively. There were $2.6 \%$ of patients who acquired a new ulcer in hospital. Among those who came from their own home, $53.8 \%$ were discharged back home, $28.2 \%$ to rehabilitation and $18.0 \%$ to residential/nursing care (Table 1).

Compared with patients admitted with hip fractures, patients admitted with cervical fractures had higher rates of acute delirium without a history of dementia on admission (9.8\% versus $19.4 \%, p=0.014)$, development of a new pressure ulcer in hospital $(1.5 \%$ versus $16.7 \%, p<0.001)$, and discharge to residential or nursing care $(5.7 \%$ versus $15.9 \%$, $p=0.002$ ) (Fig. 1).

The rates of acute delirium without a history of dementia were also higher in patients with a history of stroke, ischaemic heart disease, and aged $\geq 80$ years. The rates of new pressure ulcers acquired in hospital were higher in patients with cervical fractures than those with hip fractures, staying in hospital $\geq 2$ weeks, and those with a history of diabetes. Among those who were admitted from their own home, higher proportions of those who were discharged to residential/nursing care were observed for patients admitted with cervical fractures than those with hip fractures, staying in hospital $\geq 2$ weeks, and patients with underlying dementia, Parkinson's disease or diabetes, and those aged $\geq 80$ years (Table 2).

Stepwise multivariate logistic regression showed that acute delirium without history of dementia was increased

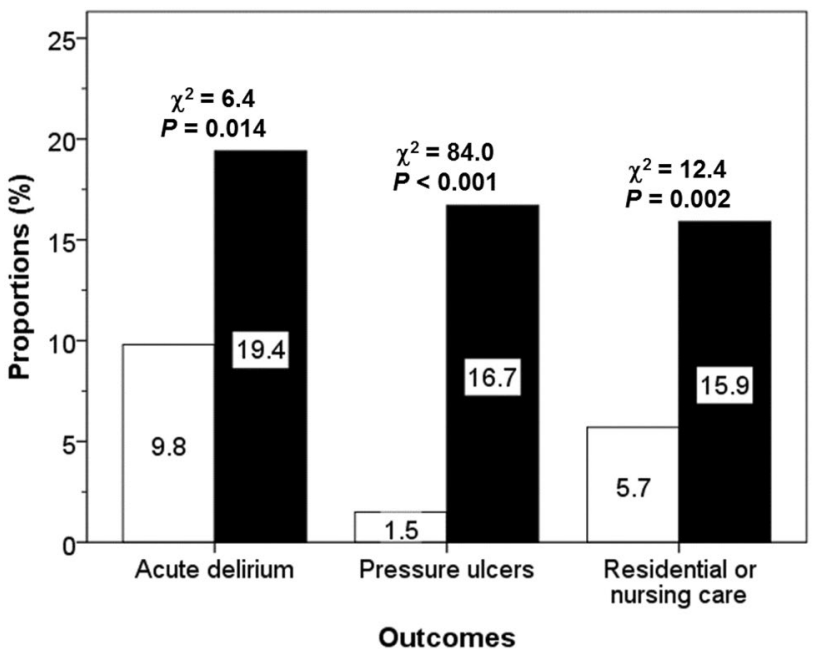

Fig. 1 Rates of acute delirium on admission, new pressure ulcers and discharge to residential/nursing care in patients admitted with cervical (open bars) or with hip fractures (black bars): Chi-squared tests showing group differences for each outcome

with cervical fractures: odds ratio $(\mathrm{OR})=2.4,95 \%$ confidence interval $(\mathrm{CI})=1.3-4.7$, aged $\geq 80$ years: $\mathrm{OR}=3.5$ (95\% CI $=1.9-6.4)$, history of stroke: $\mathrm{OR}=1.8(95 \%$ $\mathrm{CI}=1.0-3.1)$ and ischaemic heart disease: $\mathrm{OR}=1.9(95 \%$ $\mathrm{CI}=1.1-3.6)$; and pressure ulcers was increased with cervical fractures: $\mathrm{OR}=10.9(95 \% \mathrm{CI}=5.3-22.7)$, LOS between 2 and 3 weeks: $\mathrm{OR}=3.0(95 \% \mathrm{CI}=1.2-7.5)$ and $\mathrm{LOS} \geq 3$ weeks: $\mathrm{OR}=4.9,95 \% \mathrm{CI}=2.2-11.0$. After excluding four cases $(3.9 \%)$ with collar-related ulcers in patients with cervical fractures, pressure ulcers in cervical fractures remained greater than in hip fractures: $\mathrm{OR}=9.4(95 \%$
Table 1 Subject characteristics of 102 (56 men, 46 women) patients admitted with cervical fractures with mean age of 82.7 years $(\mathrm{SD} \pm 9.8)$ and 1257 (350 men, 907 women) patients admitted with hip fractures with mean age of $83.9(\mathrm{SD} \pm 8.6)$

\begin{tabular}{ll}
\hline & $\%$ \\
\hline Demographics & \\
Admitted from home: nursing/residential care: rehabilitation & $81.3: 12.0: 6.7$ \\
Men: women & $29.9: 70.1$ \\
Age $<80$ years: $\geq 80$ years & $28.6: 71.4$ \\
Outcomes & $7.5: 92.5$ \\
Cervical fractures: hip fractures & 10.6 \\
Acute delirium without dementia & $68.7: 15.7: 15.6$ \\
LOS in hospital<2 weeks: $2-3$ weeks: $\geq 3$ weeks & 2.6 \\
Pressure ulcers & $53.8: 28.2: 18.0$ \\
Discharged to own home: rehabilitation: nursing/residential care & \\
Coexisting morbidities & 28.6 \\
Dementia & 15.2 \\
Stroke & 4.2 \\
Parkinson's disease & 9.9 \\
Ischaemic heart disease & 13.5 \\
Diabetes & \\
\hline
\end{tabular}

A total of 1359 patients (406 men, 953 women) aged 83.8 years $(S D \pm 8.7)$ 
Table 2 Proportions of patients with different outcomes

\begin{tabular}{|c|c|c|c|c|c|c|c|c|c|}
\hline & $\begin{array}{l}\text { Acute } \\
\text { delirium } \\
(\%)^{*}\end{array}$ & $\chi^{2}$ & $p$ & $\begin{array}{l}\text { Pressure } \\
\text { ulcers }(\%)\end{array}$ & $\chi^{2}$ & $p$ & $\begin{array}{l}\text { Discharge to residential } \\
\text { or nursing care }(\%)\end{array}$ & $\chi^{2}$ & $p$ \\
\hline Length of stay $<2$ weeks & 8.4 & 18.5 & $<0.001$ & 1.3 & 22.9 & $<0.001$ & 3.2 & 60.8 & $<0.001$ \\
\hline Length of stay 2-3 weeks & 12.6 & & & 4.7 & & & 8.1 & & \\
\hline Length of stay $\geq 3$ weeks & 23.1 & & & 6.6 & & & 20.6 & & \\
\hline No dementia & - & - & - & 2.8 & 0.2 & 0.391 & 4.3 & 30.9 & $<0.001$ \\
\hline Dementia & - & & & 2.3 & & & 14.9 & & \\
\hline No stroke & 9.5 & 7.1 & 0.009 & 2.2 & 3.4 & 0.061 & 6.1 & 0.5 & 0.299 \\
\hline Stroke & 17.6 & & & 4.4 & & & 7.6 & & \\
\hline No Parkinson's disease & 10.4 & 1.4 & 0.176 & 2.5 & 0.2 & 0.438 & 5.9 & 8.7 & 0.011 \\
\hline Parkinson's disease & 16.7 & & & 3.5 & & & 17.5 & & \\
\hline No ischaemic heart disease & 9.8 & 5.6 & 0.019 & 2.6 & 0.1 & 0.488 & 6.1 & 0.7 & 0.266 \\
\hline Ischaemic heart disease & 18.0 & & & 3.0 & & & 8.2 & & \\
\hline No diabetes & 11.0 & 0.6 & 0.282 & 2.2 & 6.5 & 0.016 & 5.8 & 3.8 & 0.046 \\
\hline Diabetes & 8.6 & & & 5.5 & & & 10.1 & & \\
\hline Age $<80$ years & 4.5 & 17.3 & $<0.001$ & 1.5 & 2.6 & 0.074 & 2.6 & 12.2 & $<0.001$ \\
\hline Age $\geq 80$ years & 13.8 & & & 3.1 & & & 8.2 & & \\
\hline Women & 10.2 & 0.5 & 0.280 & 2.5 & 0.2 & 0.384 & 6.7 & 0.6 & 0.261 \\
\hline Men & 11.7 & & & 3.0 & & & 5.4 & & \\
\hline
\end{tabular}

*Only patients without dementia were included in delirium analysis

Four patients (3.9\%) admitted with cervical fractures developed pressure ulcers in the neck area

$\mathrm{CI}=4.9-21.3)$. Among those who came from their own home, discharge to residential/nursing care was increased with cervical fractures: $\mathrm{OR}=3.2(95 \% \mathrm{CI}=1.4-7.0)$, LOS $\geq 3$ weeks: $O R=4.4(95 \% \mathrm{CI}=2.5-7.6)$, dementia: $\mathrm{OR}=2.7$ (95\% CI=1.6-4.7), Parkinson's disease: $\mathrm{OR}=3.4$ $(95 \% \mathrm{CI}=1.3-8.8)$, and aged $\geq 80$ years: $\mathrm{OR}=2.7(95 \%$ $\mathrm{CI}=1.3-5.6$ ) (Table 3 ). The use of age as continuous variable did not substantially change the ORs for all outcomes above.

\section{Discussion}

The present study observed that compared with hip fracture, cervical fracture was more likely to associate with acute delirium by 2.4 -fold, pressure ulcers by 10.9 -fold and discharge to residential/nursing care by 3.2 -fold, independent of other established risk factors. Our findings are novel since, as far as we are aware, no previous studies have simultaneously analysed the relative contributions of the types of fracture towards clinical outcomes. More research is warranted to identify underlying causes of these poor outcomes to establish and implement guidelines in clinical practice which may further improve the management and minimise the level of risk in such group of patients.

The observation of more patients admitted with hip fractures $(92.5 \%)$ than those with cervical fracture $(7.5 \%)$ over the same period of study are almost the same as figures $(93.8 \%$ versus $6.2 \%)$ reported from a large study of US patients [14]. The proportions of women and men (72.2\% versus $27.8 \%$ ) admitted with hip fractures were similar to figures reported from studies of high income countries [4] and the slightly greater number of men than women (54.9\% versus $45.1 \%)$ with cervical fractures is also similar to those reported from other studies [9, 12, $14,21]$. Most of the cervical fractures were due to falls, which are again consistent with previous reports [9]. On the other hand, the aetiologies of cervical fractures in younger adults ( $<60$ years) are very different, mostly arising from contact and collision sports such as rugby [22], football, gymnastics [23] and diving [24], as well as road traffic accidents [8].

Although cervical and hip fractures are both age-related acute conditions, approaches to their management are highly contrasting. In the UK, national audit and guidelines for management of hip fractures have been well established and updated regularly [16]. The emphasis on specialist orthogeriatric oversight within $72 \mathrm{~h}$, early restorative surgery and mobilisation by physiotherapists 1 day after surgery reflect an intensive intervention strategy. The most recent NHFD report showed the national average for achieving key performance indicators ranged between 69 and 90\%. The delivery of these interventions has coincided with progressive reduction in 30-day mortality since 2007 [16]. 
Table 3 Predictive models constructed by multivariate stepwise logistic regression simultaneously analysing cervical and hip fractures with all established risk factors (shown in Table 2) to predict clinical outcome measures

\begin{tabular}{|c|c|c|c|}
\hline \multicolumn{4}{|c|}{ Acute delirium without a history of dementia } \\
\hline Risk factors & OR & $95 \%$ CI & $p$ \\
\hline Hip fractures & 1 & - & - \\
\hline Cervical fractures & 2.4 & $1.3-4.7$ & 0.008 \\
\hline Age $<80$ years & 1 & - & - \\
\hline Age $80 \geq$ years & 3.5 & $1.9-6.4$ & $<0.001$ \\
\hline No stroke & 1 & - & - \\
\hline Stroke & 1.8 & $1.0-3.1$ & 0.041 \\
\hline No ischaemic heart disease & 1 & - & - \\
\hline Ischaemic heart disease & 1.9 & $1.1-3.6$ & 0.033 \\
\hline \multicolumn{4}{|l|}{ Pressure ulcers } \\
\hline Risk factors & OR & $95 \% \mathrm{CI}$ & $p$ \\
\hline Hip fractures & 1 & - & - \\
\hline Cervical fractures* & 10.9 & $5.3-22.7$ & $<0.001$ \\
\hline Length of stay $<2$ weeks & 1 & - & - \\
\hline Length of stay $2-3$ weeks & 3.0 & $1.2-7.5$ & 0.022 \\
\hline Length of stay $\geq 3$ weeks & 4.9 & $2.2-11.0$ & $<0.001$ \\
\hline \multicolumn{4}{|c|}{ Discharged to residential/nursing care } \\
\hline Hip fractures & 1 & - & - \\
\hline Cervical fractures & 3.2 & $1.4-7.0$ & 0.004 \\
\hline Length of stay $<2$ weeks & 1 & - & - \\
\hline Length of stay $\geq 3$ weeks & 4.4 & $2.5-7.6$ & $<0.001$ \\
\hline No dementia & 1 & - & - \\
\hline Dementia & 2.7 & $1.6-4.7$ & $<0.001$ \\
\hline No Parkinson's disease & 1 & - & - \\
\hline Parkinson's disease & 3.4 & $1.3-8.8$ & 0.012 \\
\hline Age $<80$ years & 1 & - & - \\
\hline Age $80 \geq$ years & 2.7 & $1.3-5.6$ & 0.010 \\
\hline
\end{tabular}

*Excluding four cases with collar-related ulcers: $\mathrm{OR}=9.4(95 \% \mathrm{CI}=4.9-21.3)$

By contrast, the nationally reported performance and ongoing audit and review of cervical fracture management does not seem to be subject to any form of national organised review and there are no existing key performance indicators or other targets set out for this group of patients in the UK. Most existing literature appears to focus on immediate management such as neck immobilisation and rapid diagnosis of cervical fractures [7, 25]. Management of patients with cervical fractures is usually conservative, with bed rest and immobilisation forming the mainstay of therapy. Surgery for cervical fractures is much less commonly performed than for hip fractures: only in circumstances such as unstable fractures or spinal cord compression [26, 27]. A number of factors may influence the decision for not operating cervical fractures, including the greater complexity of the cervical spine and age of the patients. Compared with patients who did not receive surgery for cervical fractures, early mortality rates (at 1 month or at 3 months) after surgery were lower in the younger group (65-74 years), but higher in older individuals (over 85 years) [12]. Bed rest seems to be associated with a number of complications including pressure ulcers, thromboembolism and residual immobility. Although the standard practice is to advise the patient to sit in a chair for a certain period of time as soon as possible, this varies widely between National Health Service hospitals. There is therefore an urgent need for standardised national guidelines on management of cervical fractures similar to those for management of hip fractures.

Orthotic devices, such as C-collars, Miami J-collars and halo-fixation devices are commonly used in cervical fractures [28]. Collars are responsible for device-related pressure ulcers due to an increased load on the soft tissue of the neck and surround areas that is usually not adapted for bearing pressure [29]. The commonly observed delirium 
in patients with cervical fractures presents a major challenge in management of this group of patients as many are not able to tolerate support collars, and delirium may be exacerbated by their use. It should be recognised that the association of cervical fractures and co-morbidities with delirium should not be interpreted as there being causal links, as their relationships are often reciprocal.

The observation of higher proportions of patients with cervical fractures being transferred to residence of higher level of care than those of patients with hip fractures suggests poorer recovery among patients with cervical fractures. Previous studies have found that cervical fractures led to long term disability in over half of patients [26, 27]. The majority of patients with cervical fractures acquired pressure ulcers in other areas not caused by the collar, and the higher proportion of non-collar related pressure pressures in these patients than that of patients with hip fractures. It is possible that these differences may be due to immobility and severity, or current management approach of cervical fractures. Pressure ulcers tend to develop rapidly in patients who are unable to shift their weight distribution regularly, which may be the case with cervical fractures. Pressure ulcers are an important indicator of quality of patient care. They impact adversely on patient safety and experience and carry a financial burden for the National Health Service, with the annual cost of $£ 1382$ for wound care per patient with a category 1 pressure ulcer, rising to an excess of $£ 8500$ per patient with a category $\geq 2$ pressure ulcer [30].

There are certain limitations in our study including its cross-sectional design and relatively small numbers of patients with cervical fractures. Thus other outcomes such mortality could not be examined and this caveat should be appreciated when interpreting our findings. Future studies with larger numbers of patients with cervical fractures would be helpful to support our findings with greater confidence. The strengths of our study lie in its wide range of clinical measures for multivariate stepwise analysis to identify the most influential factors, including chronic conditions that indicate the individual's frailty, and allow adjustment of potential confounding effects from each other. The demographic distributions such as age and sex, and proportions of different types of fractures were very similar to those reported for patients admitted to hospital in high income countries (see above), and thus provide confidence in the findings from our study.

In conclusion, compared with hip fracture, cervical fracture is more likely to associate with acute delirium and pressure ulcers, and for discharge to residency of high level of care, independent of established risk factors.

Acknowledgements We are grateful to all patients who participated in this study as part of the NHFD Audit Programme.
Author contributions TSH reviewed the topic-related literature and was responsible for the study concept and design. RL, KY and AO performed the study coordination and data collection. TSH and JB co-wrote the first draft. TSH analysed, interpreted the data and revised the manuscript. JR, DF and CHF edited the manuscript. All authors checked, interpreted the results and approved the final version.

\section{Compliance with ethical standards}

Conflict of interest The authors declare that they have no conflicts of interest.

Ethical approval This study does not require National Health Service Research Ethics Committee approval since it involves secondary analysis of anonymised data. This study was conducted in accordance with the 1964 Helsinki Declaration and its later amendments or comparable ethical standards.

Human and animal rights This article does not contain any studies with animals performed by any of the authors. Informed consent Informed consent was obtained from all individual participants included in the study.

Informed consent Informed consent was obtained from all individual participants included in the study.

Open Access This article is licensed under a Creative Commons Attribution 4.0 International License, which permits use, sharing, adaptation, distribution and reproduction in any medium or format, as long as you give appropriate credit to the original author(s) and the source, provide a link to the Creative Commons licence, and indicate if changes were made. The images or other third party material in this article are included in the article's Creative Commons licence, unless indicated otherwise in a credit line to the material. If material is not included in the article's Creative Commons licence and your intended use is not permitted by statutory regulation or exceeds the permitted use, you will need to obtain permission directly from the copyright holder. To view a copy of this licence, visit http://creativecommons.org/licenses/by/4.0/.

\section{References}

1. Curtis EM, Moon RJ, Harvey NC, Cooper C (2017) Reprint of: the impact of fragility fracture and approaches to osteoporosis risk assessment worldwide. Int J Orthop Trauma Nurs 26:7-17

2. Hernlund $E$, Svedbom A, Ivergård $M$, Compston J, Cooper C, Stenmark J, McCloskey EV, Jönsson B, Kanis JA (2013) Osteoporosis in the European Union: medical management, epidemiology and economic burden. Arch Osteoporos 8(1-2):136

3. Veronese N, Maggi S (2018) Epidemiology and social costs of hip fracture. Injury 49:1458-1460

4. Johnell O, Kanis JA (2004) An estimate of the worldwide prevalence, mortality and disability associated with hip fracture. Osteoporos Int 15:897-902

5. Tajeu GS, Delzell E, Smith W, Arora T, Curtis JR, Saag KG, Morrisey MA, Yun H, Kilgore ML (2014) Death, debility, and destitution following hip fracture. J Gerontol A Biol Sci Med Sci 69:346-353

6. Williamson S, Landeiro F, McConnell T, Fulford-Smith L, Javaid MK, Judge A, Leal J (2017) Costs of fragility hip fractures globally: a systematic review and meta-regression analysis. Osteoporos Int 28:2791-2800 
7. College of Emergency Medicine Clinical Effectiveness Committee (2010) Guideline on the management of alert, adult patients with a potential cervical spine injury in the Emergency Department. College of Emergency Medicine, London

8. Watanabe M, Sakai D, Yamamoto Y, Sato M, Mochida J (2010) Upper cervical spine injuries: age-specific clinical features. J Orthop Sci 15:485-492

9. Asemota AO, Ahmed AK, Purvis TE, Passias PG, Goodwin CR, Sciubba DM (2018) Analysis of cervical spine injuries in elderly patients from 2001 to 2010 using a nationwide database: increasing incidence, overall mortality, and inpatient hospital charges. World Neurosurg 120:e114-e130

10. Menendez ME, Ring D, Harris MB, Cha TD (2015) Predicting in-hospital mortality in elderly patients with cervical spine fractures: a comparison of the Charlson and Elixhauser comorbidity measures. Spine 40:809-815

11. Sokolowski MJ, Jackson AP, Haak MH, Meyer MDPR Jr, Sokolowski MS (2007) Acute outcomes of cervical spine injuries in the elderly: atlantaxial vs subaxial injuries. J Spinal Cord Med 30:238-242

12. Harris MB, Reichmann WM, Bono CM, Bouchard K, Corbett KL, Warholic N, Simon JB, Schoenfeld AJ, Maciolek L, Corsello P, Losina E (2010) Mortality in elderly patients after cervical spine fractures. J Bone Joint Surg Am 92:567-574

13. Venkatesan M, Northover JR, Wild JB, Johnson N, Lee K, Uzoigwe CE, Braybrooke JR (2014) Survival analysis of elderly patients with a fracture of the odontoid peg. Bone Joint $\mathbf{J}$ 96-B:88-93

14. Cooper Z, Mitchell SL, Lipsitz S, Harris MB, Ayanian JZ, Bernacki RE, Jha AK (2015) Mortality and readmission after cervical fracture from a fall in older adults: comparison with hip fracture using national Medicare data. J Am Geriatr Soc 63:2036-2042

15. Peck GE, Shipway DJ, Tsang K, Fertleman M (2018) Cervical spine immobilisation in the elderly: a literature review. Br J Neurosurg 32:286-290

16. Royal College of Physicians (2019) National hip fracture database annual report 2019. Royal College of Physicians, London

17. Lisk R, Yeong K, Enwere P, Jenkinson J, Robin J, Irvin-Sellers M, Fluck D, Osmani A, Sharmin R, Sharma P, Fry CH, Han TS (2020) Associations of 4AT with mobility, length of stay and mortality in hospital and discharge destination among patients admitted with hip fractures. Age Ageing 49:411-417

18. Lisk R, Yeong K, Fluck D, Fry CH, Han TS (2020) The ability of the Nottingham hip fracture score to predict mobility, length of stay and mortality in hospital, and discharge destination in patients admitted with a hip fracture. Calcif Tissue Int. https:// doi.org/10.1007/s00223-020-00722-2 (Online ahead of print)

19. Han TS, Yeong K, Lisk R, Fluck D, Fry CH (2020) Prevalence and consequences of malnutrition and malnourishment in older individuals admitted to hospital with a hip fracture. Eur J Clin Nutr. https://doi.org/10.1038/s41430-020-00774-5 (Online ahead of print)

20. World Health Organization (2004) ICD-10: international statistical classification of diseases and related health problems: tenth revision. WHO, Geneva

21. Malik SA, Murphy M, Connolly P, O’Byrne J (2008) Evaluation of morbidity, mortality and outcome following cervical spine injuries in elderly patients. Eur Spine J 17:585-591

22. Quarrie KL, Cantu RC, Chalmers DJ (2002) Rugby union injuries to the cervical spine and spinal cord. Sports Med 32:633-653

23. Zmurko MG, Tannoury TY, Tannouty CA, Anderson DG (2003) Cervical sprains, disc herniations, minor fractures, and other cervical injuries in the athlete. Clin Sports Med 22:513-521

24. Bárbara-Bataller E, Méndez-Suárez JL, Alemán-Sánchez C, Sánchez-Enríquez J, Sosa-Henríquez M (2017) Spinal cord injuries resulting from diving accidents in the Canary Islands. Neurocirugía 28:183-189

25. National Institute for Health and Clinical Excellence. Spinal injury: assessment and initial management. NICE guideline [NG41]. Published date: 17 Feb 2016

26. McMordie JH, Viswanathan VK, Gillis CC (2020) Cervical Spine Fractures Overview. Treasure Island (FL): StatPearls Publishing. https://www.ncbi.nlm.nih.gov/books/NBK448129/. Accessed 15 Jul 2020

27. Torlincasi AM, Waseem M. Cervical Injury (2020) Treasure Island (FL): StatPearls Publishing. Jan- https://www.ncbi.nlm. nih.gov/books/NBK448146/. Accessed 15 Jul 2020

28. Worsley PR, Stanger ND, Horrell AK, Bader DL (2018) Investigating the effects of cervical collar design and fit on the biomechanical and biomarker reaction at the skin. Med Devices (Auckl) 11:87-94

29. Lacey L, Palokas M, Walker J (2019) Preventative interventions, protocols or guidelines for trauma patients at risk of cervical collar-related pressure ulcers: a scoping review. JBI Database System Rev Implement Rep 17:2452-2475

30. Guest JF, Fuller GW, Vowden P, Vowden KR (2018) Cohort study evaluating pressure ulcer management in clinical practice in the UK following initial presentation in the community: costs and outcomes. BMJ Open 8:e21769

Publisher's Note Springer Nature remains neutral with regard to jurisdictional claims in published maps and institutional affiliations. 